\title{
Analisis Kebutuhan Media Pembelajaran Bermuatan Nilai-Nilai Karakter Islami Pada Materi Fisika
}

\author{
Fitriyani $^{1}$, Hadma Yuliani ${ }^{2}$, Mukhlis Rohmadi ${ }^{3}$ \\ 1,2,3 Program Studi Tadris (Pendidikan) Fisika, IAIN Palangka Raya, \\ J1. G.Obos Komplek Islamic Center Palangka Raya \\ Email : fitriyani16011@gmail.com
}

\begin{abstract}
This research was conducted because of the challenges of 21 st century education which requires students to be proficient in learning, digital literate, and have a strong character. The purpose of this study was to conduct a needs analysis for designing physics learning media. Needs analysis is carried out through literature studies and field studies. Study literature by collecting information about instructional media, the importance of character building, and the study of physics material that needs strengthening. Field studies were conducted to determine learning in class. The results of the literature study show that the eXe-Learning application has advantages that can be used in making learning media, character planting is needed according to the curriculum and conditions in the field and it is also known that the material that needs strengthening is Newton's Law of Gravity and Kepler's Law. The results of the analysis of the needs of 22 students of class X IPA obtained that $86.4 \%$ did not have handbooks, $68.2 \%$ had difficulty learning physics. In fact, $86.4 \%$ enjoyed learning with the media. However, based on teacher information shows that the use of media in learning is still rare. And also as many as $90.9 \%$ want alternative teaching materials for learning physics and $95.5 \%$ agree if there is an electronic module of physics material that contains Islamic character values in it as a learning resource. This was also agreed by the teacher because of the madrasah-based school background. These results indicate that it is necessary to develop instructional media that contains Islamic character values in physics material.
\end{abstract}

Keywords: needs analysis, physics learning media, Islamic character values.

\begin{abstract}
Abstrak: Penelitian ini dilakukan karena adanya tantangan pendidikan abad 21 yang menuntut siswa mahir dalam pembelajaran, melek digital, dan memiliki karakter yang kuat. Tujuan penelitian ini adalah melakukan analisis kebutuhan perancangan media pembelajaran fisika. Analisis kebutuhan dilakukan melalui studi literatur dan studi lapangan. Studi literatur dengan mengumpulkan informasi tentang media pembelajaran, pentingnya pembentukan karakter, dan pembelajaran materi fisika yang perlu diperkuat. Studi lapangan dilakukan dengan menganalisis pembelajaran di kelas. Hasil studi pustaka menunjukkan bahwa aplikasi eXe-Learning memiliki kelebihan yaitu dapat digunakan dalam pembuatan media pembelajaran, penanaman karakter dibutuhkan sesuai dengan kurikulum dan kondisi di lapangan serta diketahui juga bahwa materi yang perlu diperkuat adalah Hukum Newton tentang Gravitasi dan Hukum Kepler. Hasil analisis kebutuhan 22 siswa kelas X IPA diperoleh 86,4\% tidak memiliki buku pegangan, $68,2 \%$ kesulitan belajar fisika, dan $86,4 \%$ menikmati pembelajaran dengan media. Namun berdasarkan informasi guru, penggunaan media masih jarang dilakukan. Sebanyak 90,9\% menginginkan bahan ajar alternatif untuk pembelajaran fisika dan $95,5 \%$ setuju jika terdapat modul elektronik materi fisika yang memuat nilai karakter islami di dalamnya sebagai sumber belajar. Hal ini juga disetujui oleh guru karena latar belakang sekolah berbasis madrasah. Hasil tersebut menunjukkan bahwa perlu dikembangkan media pembelajaran yang mengandung nilai-nilai karakter islami dalam materi fisika.
\end{abstract}

Kata kunci: analisis kebutuhan, media pembelajaran fisika, nilai-nilai karakter islami. 


\section{PENDAhUluan}

Tantangan pendidikan pada abad 21 ini ditandai dengan perkembangan teknologi yang pesat. Dengan adanya tantangan pendidikan seperti ini maka perlu adanya penguatan dalam dunia pendidikan untuk bisa mencapai tujuan pendidikan nasional. Tujuan pendidikan dalam UU Nomor 20 Tahun 2003 tentang Sistem Pendidikan Nasional adalah untuk berkembangnya potensi peserta didik agar menjadi manusia yang beriman dan bertakwa kepada Tuhan Yang Maha Esa, berakhlak mulia, sehat, berilmu, cakap, kreatif, mandiri, dan menjadi warganegara yang demokratis serta bertanggung jawab. Ilmu Pengetahuan Alam (IPA) menjadi salah satu landasan penting dalam pembangunan bangsa. Sehingga, pembelajaran IPA diharapkan dapat menghantarkan siswa memenuhi kemampuan keterampilan belajar dan berinovasi, terampil menggunakan media dan TIK serta kemampuan untuk menjalani kehidupan dan karir (Kementerian Pendidikan dan Kebudayaan, 2017). Hal ini juga sesuai dengan tulisan Trilling dan Fadel bahwa ketiga kemampuan tersebut merupakan tantangan pendidikan di abad 21 ini (Trilling \& Fadel, 2009).

Ketiga kemampuan diatas merupakan keterampilan-keterampilan yang hendaknya dapat dicapai oleh siswa melalui bangku pendidikan. Jika dicermati, katagori keterampilan pertama dan ketiga merupakan implementasi dari pendidikan karakter serta katagori keterampilan kedua berkaitan dengan kemampuan dalam penguasaan teknologi baik informasi maupun komunikasi. Sehingga sangat penting untuk penguatan penanaman karakter dan penguatan keterampilan penguasaan media dan teknologi dalam pendidikan. Kualitas pendidikan dapat ditingkatkan dari beberapa aspek yang salah satunya adalah aspek penyokong proses pembelajaran yaitu sumber belajar (Hendriyani dkk., 2018).

Pada penelitian yang akan dilaksanakan ini yaitu untuk mengembangkan suatu sumber belajar jenis media pembelajaran. Media pembelajaran yang dimaksud berupa bahan belajar bagi peserta didik yang ditujukan berbasis online. Sehingga, penelitian terlebih dahulu diperlukan studi pendahuluan. Studi pendahuluan ini terdiri atas studi literatur dan studi lapangan. Studi literatur dilakukan untuk mengumpulkan informasi secara umum mengenai apa saja yang perlu dilakukan untuk memberikan perubahan menjadi lebih baik lagi dalam kegiatan pembelajaran. itu, studi lapangan juga dilakukan. Studi lapangan dilakukan untuk mengetahui kondisi pembelajaran di sekolah. Uraian ini juga sejalan dengan Arizal Fadli bahwa studi lapangan dilakukan untuk mengetahui kondisi objek di lapangan dengan mengumpulkan berbagai informasi seperti analisis kebutuhan guru dan siswa terhadap bahan ajar atau media pembelajaran (Fadli dkk., 2017).

Bahan belajar peserta didik yang dikembangkan berupa modul pembelajaran. Modul pembelajaran tersebut ditujukan berbasis TIK yaitu Teknologi Informasi dan Komunikasi sebagai media yang dapat memuat teks, grafik, gambar, animasi, serta video pembelajaran. Hal ini sejalan dengan tulisan Mussoi bahwa penggunaan komputer dan internet dalam proses pendidikan, ditambah dengan alat komputasi berupa perangkat lunak pendidikan, maka akan dapat berkontribusi pada proses belajar mengajar sehingga memungkinkan peserta didik dapat lebih mudah untuk memahami prinsip-prinsip teoretis Ilmu Pengetahuan Alam (Mussoi, 2011). Maka dari itu, pembelajaran di kelas dapat dilakukan inovasi dengan adanya penggunaan modul elektronik terlebih jika modul tersebut bisa diakses peserta didik tidak hanya di kelas saja.

E-module atau modul elektronik adalah seperangkat media pengajaran digital yang disusun secara sistematis sebagai upaya belajar mandiri. Perbedaannya dengan modul biasa hanya dari jenisnya saja yaitu cetak dan elektronik. Salah satu cara untuk membuat suatu e-module adalah menggunakan aplikasi eXe-Learning. Whyles, R menyatakan bahwa $e X e$ sebagai alat penulisan berguna untuk membantu guru agar mudah mempublikasikan kegiatan belajar berbasis web yang terstruktur (Wyles, 2006). Mussoi menyatakan bahwa eXe-Learning (e-learning XHTML 
Editor-Learning) adalah program penulisan di mana guru dapat mengembangkan dan menerbitkan materi pembelajaran tanpa perlu keahlian dalam menguasai bahasa pemrograman (Mussoi, 2011). Sehingga eXe-Learning adalah perangkat yang memungkinkan penggunanya untuk bisa menunjang proses pembelajaran melalui media elektronik . Intan Kurniasari (2018) menyebutkan kelebihan aplikasi ini yaitu dapat memuat komponen penguat materi pelajaran seperti video, animasi, percobaan virtual serta pengoperasiannya dapat memudahkan pemula tanpa harus mempelajari bahasa pemrograman web. Penelitian Lisyanti (2019) juga menunjukkan bahwa kelebihan aplikasi eXe-Learning ini adalah dapat diakses secara online maupun offline serta dapat memuat soal-soal interaktif. Selain itu, aplikasi eXe-Learning ini yaitu dapat digunakan tidak hanya dengan laptop atau komputer saja tetapi juga smartphone. Kelebihan-kelebihan tersebut dapat memudahkan dalam hal pengunaannya serta diharapkan dapat menarik perhatian peserta didik untuk belajar.

Hasil studi literatur terhadap kebutuhan pengembangan media ini dapat bermanfaat untuk bisa mengetahui bagaimana media yang tepat berdasarkan teori-teori dan penelitian terdahulu. Sehingga dapat disusun upaya yang terbaik untuk penyelesaian masalah pendidikan secara umum. Selain itu pula diperlukan studi lapangan. Menurut Fadli, hasil studi lapangan dapat memberikan manfaat yakni mengetahui kebutuhan guru akan media pembelajaran yang sesuai dan nantinya dapat membantu siswa memahami konsep, mengetahui kebutuhan siswa terhadap media pembelajaran, serta menganalisis pelaksanaan pembelajaran di kelas (Fadli dkk., 2017).

Tujuan dari penelitian analisis kebutuhan ini adalah : (1) mengetahui kebutuhan guru akan media pembelajaran yang sesuai (2) mengetahui kebutuhan siswa terhadap media pembelajaran.

\section{METODE PENELITIAN}

Pada penelitian ini, metode awal dilakukan observasi terhadap teori-teori pendukung dilakukannya penelitian pengembangan ini. Teori serta penelitian terdahulu yang dicari yaitu terkait dengan pengembangan media eXe-Learning, muatan karakter islami, serta teori pendukung materi fisika yang akan dibahas dalam produk pengembangan. Pada pelaksanaan studi lapangan, sampel yang digunakan sampel jenuh. Subjek penelitiannya adalah siswa kelas X MIA MA Hidayatul Insan Palangka Raya yang berjumlah 22 siswa serta guru 1 orang. Metode penelitian ini adalah metode penelitian deskriptif. Pelaksanaan studi lapangan dilakukan pada Kamis 23 Januari 2020. Data yang dikumpulkan berupa hasil wawancara analsis kebutuhan guru, angket analisis kebutuhan siswa serta hasil wawancara pelaksanaan pembelajaran kepada guru dan siswa. Analisis data yang dilakukan berupa analisis data kualitatif serta analisis data kuantitatif dari hasil angket. Anget ditulis berbentuk Skala Likert dnegan instrumen berbentuk check list. Persamaan yang digunakan yaitu:

Persentase hasil $=\frac{\text { jumlah peserta didik yang menjawab }}{\text { Total keseluruhan peserta didik }} \times 100 \%$

\section{HASIL DAN PEMBAHASAN}

\subsection{Hasil dan Pembahasan Kebutuhan Guru akan Media Pembelajaran}

Analisis kebutuhan guru terhadap media pembelajaran dilakukan melalui proses wawancara dengan pedoman wawancara sebagai berikut:

3.1.1 Bahan ajar dan media jenis apa yang sering digunakan saat proses pembelajaran?

3.1.2 Apa motivasi bapak memilih bahan ajar dan media tersebut dalam proses pembelajaran? 
3.1.3 Bagaimana pendapat bapak mengenai buku pegangan peserta didik dari aspek tampilan dan kelengkapan informasinya?

3.1.4 Bagaimana menurut bapak mengenai buku atau modul pembelajaran berbasis aplikasi?

3.1.5 Apakah bapak pernah menggunakan bahan ajar berbasis aplikasi? Jika pernah, aplikasi apa yang pernah bapak gunakan?

3.1.6 Bagaimana suasana pembelajaran di kelas saat bapak mengajar?

Tabel 1 Analisis respon guru saat observasi

\begin{tabular}{|c|c|}
\hline No & Analisis Pertanyaan \\
\hline 1 & $\begin{array}{l}\text { Bahan ajar yang digunakan berupa buku teks yang dipegang guru. Buku siswa } \\
\text { untuk materi-materi awal pembelajaran tiap semester masih belum ada. Untuk } \\
\text { media yang digunakan berbasis power point dan penampilan video }\end{array}$ \\
\hline 2 & $\begin{array}{l}\text { Motivasi guru dalam menggunakan media pembelajaran tersebut karena ingin } \\
\text { mempermudah proses pemahaman siswa terhadap pembelajaran. }\end{array}$ \\
\hline 3 & $\begin{array}{l}\text { Pendapat guru mengenai buku pegangan peserta didik dari aspek tampilan dan } \\
\text { kelengkapan informasinya sudah cukup baik. }\end{array}$ \\
\hline 4 & $\begin{array}{l}\text { Pendapat guru terhadap buku pegangan siswa akan tetapi akan lebih baik kalau } \\
\text { diperkuat kembali dengan adanya media pembelajaran }\end{array}$ \\
\hline 5 & $\begin{array}{l}\text { Pendapat guru mengenai bahan ajar berbasis aplikasi sangat positif. dari aspek } \\
\text { tampilan dan kelengkapan informasinya cukup bagus }\end{array}$ \\
\hline 6 & Peserta didik terlihat antusias dalam belajar jika adanya media pembelajaran \\
\hline
\end{tabular}

\subsection{Hasil dan Pembahasan Kebutuhan Siswa akan Media Pembelajaran}

Berdasarkan hasil sebaran angket pra-penelitian kepada 22 peserta didik kelas X IPA MA Hidayatul Insan Palangka Raya, diperoleh hasil yang secara rinci tertera pada tabel 2.

Tabel 2 Hasil angket kebutuhan siswa

\begin{tabular}{|c|c|c|c|c|c|}
\hline \multirow{2}{*}{ No } & \multirow{2}{*}{ Pertanyaan } & \multicolumn{2}{|c|}{ Frekuensi } & \multicolumn{2}{|c|}{ Persentase } \\
\hline & & Ya & Tidak & Ya & Tidak \\
\hline 1 & $\begin{array}{l}\text { Apakah anda memiliki buku teks atau buku pegangan } \\
\text { lain untuk belajar fisika? }\end{array}$ & 3 & 19 & $13,6 \%$ & $86,4 \%$ \\
\hline 2 & $\begin{array}{l}\text { Apakah anda menyenangi pembelajaran yang } \\
\text { menampilkan animasi ataupun video pembelajaran } \\
\text { untuk memperkuat pemahamanmu? }\end{array}$ & 19 & 3 & $86,4 \%$ & $13,6 \%$ \\
\hline 3 & $\begin{array}{l}\text { Apakah anda mencari bahan lain selain buku dari } \\
\text { sekolah untuk membantu anda dalam memahami } \\
\text { suatu materi, lewat modul atau internet? }\end{array}$ & 15 & 7 & $68,2 \%$ & $31,8 \%$ \\
\hline 4 & $\begin{array}{l}\text { Apakah anda mengalami kesulitan mempelajari } \\
\text { materi fisika dari buku tersebut? (misalnya karena } \\
\text { kelengkapan materinya, teknik penjelasan, } \\
\text { formatnya, dan lain-lain) }\end{array}$ & 15 & 7 & $68,2 \%$ & $31,8 \%$ \\
\hline 5 & $\begin{array}{l}\text { Apakah Anda membutuhkan bahan ajar alternatif } \\
\text { yang dapat digunakan untuk mempelajari materi } \\
\text { secara lebih mudah dan menarik? }\end{array}$ & 20 & 2 & $90,9 \%$ & $9,1 \%$ \\
\hline 6 & $\begin{array}{l}\text { Apakah Anda setuju jika terdapat modul elektronik } \\
\text { materi fisika yang bermuatan nilai-nilai karakter } \\
\text { Islami di dalamnya sebagai sumber belajar? }\end{array}$ & 21 & 1 & $95,5 \%$ & $4,5 \%$ \\
\hline
\end{tabular}


Tabel 3 Analisis angket siswa

\begin{tabular}{ll}
\hline No & \multicolumn{1}{c}{ Analisis Pertanyaan } \\
\hline 1 & $86,4 \%$ peserta didik tidak memiliki buku pegangan untuk belajar fisika \\
2 & $\begin{array}{l}86,4 \% \text { peserta didik menyenangi pembelajaran dengan adanya media untuk } \\
\text { memperkuat pemahamannya }\end{array}$ \\
3 & $\begin{array}{l}68,2 \% \text { mencari bahan lain selain buku dari sekolah untuk membantu anda dalam } \\
\text { memahami suatu materi, lewat modul atau internet }\end{array}$ \\
4 & $\begin{array}{l}\text { 68,2\% peserta didik mengalami kesulitan mempelajari materi fisika } \\
\text { 90,9\% peserta didik menginginkan adanya bahan ajar alternatif untuk mereka } \\
\text { belajar fisika } \\
\text { 95,5\% peserta didik setuju jika terdapat modul elektronik materi fisika yang } \\
\text { bermuatan nilai-nilai karakter islami di dalamnya sebagai sumber belajar }\end{array}$ \\
\hline
\end{tabular}

Berdasarkan tabel 3 mengenai analisis angket siswa maka dapat diketahui bahwa peserta didik memerlukan suatu bahan untuk belajar, terkait media, dan bermuatan nilai karakter islami. Penanaman karakter menjadi hal penting dalam dunia pendidikan karena pada hakikatnya pendidikan tidak hanya berupaya menjadikan manusia yang berilmu, tetapi juga menjadi pribadi yang baik. Berdasarkan liputan massa saat ini serta peristiwa yang terjadi di lingkungan sekitar menggambarkan bahwa masih rendahnya moral peserta didik dengan banyaknya kasus yang merujuk pada tidak tertanamnya karakter yang baik seperti perkelahian, bullying, serta pencurian (Taulabi \& Mustofa, 2019). Masalah lainnya yang marak terjadi saat ini seperti menyontek berjamaah saat ujian nasional, maraknya kasus korupsi, serta tindakan kekerasan di kalangan anak dan remaja (Yuliharti, 2019).

Upaya pembentukan karakter menjadi hal utama dalam pendidikan sehingga terus-menerus disampaikan dan ditanamkan dalam berbagai lingkup terutama dalam lingkup sekolah (Taulabi $\&$ Mustofa, 2019). Selain itu, proses pemahaman konsep juga sangat penting seperti dalam hal penguatan materi dan penumbuhan motivasi. Kemampuan pendidik dalam menyiapkan, menciptakan dan mengelola proses pembelajaran sangat diperlukan. Salah satu unsur penting dalam pembelajaran adalah sumber belajar yang berupa media pembelajaran. Media dalam pembelajaran penting adanya sebagai upaya agar pembelajaran menjadi lebih hidup dan menyenangkan (Priyambodo, 2010).

Salah satu materi pada pelajaran fisika SMA/MA kelas X adalah Hukum Newton tentang Gravitasi. Materi ini erat kaitannya dengan interaksi antar benda di kehidupan sehari-hari yang disebabkan oleh suatu gaya yaitu gaya gravitasi. Gaya pada umumnya dipahami bekerja dengan adanya sentuhan, tetapi gaya gravitasi bekerja tanpa melalui sentuhan dan bahkan dapat bekerja pada dua benda yang terpisah oleh jarak yang sangat jauh (Douglas, 2014 : 147). Hal ini menjadi tantangan bagi guru dalam menjelaskannya serta menjadi tantangan bagi peserta didik untuk memahaminya. Sehingga diperlukan strategi khusus untuk bisa menjelaskan konsep gaya gravitasi dan mencegah adanya miskonsepsi pada peserta didik (Yaumi dkk., 2019). Selain gaya gravitasi, pembahasan materi ini juga berkaitan dengan Hukum Kepler yaitu membahas pergerakan benda-benda langit dimana sangat diperlukan suatu penjelasan kuat terhadap fenomena tersebut. Akan tetapi, berdasarkan informasi guru bahwa pembelajaran di kelas lebih banyak mengandalkan penjelasan guru saja. Sehingga peserta didik kurang antusias dalam mengikuti pembelajaran. Masalah lain juga diketahui bahwa rasa ingin tahu peserta didik serta kebiasaan membaca materi pelajaran juga kurang maksimal yang dilihat dari kurangnya keaktifan peserta didik dalam pembelajaran. Hal ini membuat penguasaan materi juga kurang berdasarkan akumulasi nilai latihan dan ulangan harian yang masih rendah. Selain itu pula, 
kedisiplinan peserta didik dalam belajar, kerja sama serta kemampuan komunikasi perlu ditingkatkan. Salah satu karakter penting lainnya adalah peduli lingkungan terutama lingkungan sekolah yang perlu upaya lebih maksimal lagi dalam hal kebersihan lingkungan sekolah.

Permasalahan dalam pembelajaran fisika di MA Hidayatul Insan Palangka Raya ini berdasarkan analisis kebutuhan yang dilakukan memberikan arah akan pentingnya pengembangan suatu bahan ajar berupa modul pembelajaran. Modul pembelajaran tersebut hendaknya bisa memotivasi peserta didik dalam belajar, berisi materi yang lengkap untuk membantu pemahaman serta berisi uraian nilai karakter untuk menunjang tumbuhnya karakter yang baik dalam belajar. Konsep tentang karakter ini berupa karakter islami yang bersumber dari sumber hukum utama dalam Islam yakni al-Qur'an dan Hadist Nabi Muhammad SAW karena MA Hidayatul Insan merupakan sekolah berbasis Madrasah sehingga sangat penting muatan karakter islami dipelajari. Berdasarkan penelitian Muhammad Ali dan Mila Anggela (2013) diketahui bahwa upaya penanaman karakter islami melalui modul dilakukan agar pembelajaran menjadi lebih bermakna karena adanya keterkaitan antara materi, proses belajar, dan karakter yang baik dalam belajar. Sehingga berdasarkan analisis kebutuhan ini maka diperlukan suatu bahan untuk peserta didik belajar berupa modul pembelajaran elektronik yang disusun menggunakan aplikasi eXe-Learning serta bermuatan nilai-nilai karakter islami. Aplikasi ini digunakan karena berdasarkan studi literatur diperoleh data bahwa aplikasi ini dapat menunjang pembelajaran siswa karena berbasis web dan dapat digunakan dimana saja dan kapan saja baik mengguakan laptop maupun smartphone. Dimana berdasarkan observasi yang dilakukan diketahui bahwa peserta didik rata-rata telah memiliki smartphone. Materi yang perlu dikuatkan adalah materi fisika Hukum Newton tentang Gravitasi dan Hukum Kepler.

\section{KESIMPULAN}

Kesimpulan yang diperoleh yaitu (1) guru memerlukan suatu media dalam pembelajaran untuk bisa memperkuat pemahaman konsep siswa. Sehingga diperlukan satu media yang dapat memuat teks, gambar, video, animasi dan percobaan. Hal ini hendaknya bisa menjadi PR bagi kita untuk bisa mengatur setiap urusan. (2) siswa belum memiliki bahan belajar serta diperlukannya penguatan karakter dalam belajar melalui suatu media pembelajaran yang dirancang khusus untuk hak tersebut.

\section{SARAN}

Untuk penelitian selanjutnya maka dapat diketahui berdasarkan analisis kebutuhan ini bahwa diperlukannya suatu media untuk peserta didik dapat belajar mandiri, dimana saja, dan kapan saja. Media tersebut hendaknya bermuatan nilai karakter islami yang terkait dunia fisika.

\section{DAFTAR PUSTAKA}

Anggela, M. (2013). Pengembangan Buku Ajar Bermuatan Nilai-Nilai Karakter Pada Materi Usaha Dan Momentum Untuk Pembelajaran Fisika Siswa Kelas Xi Sma. Pillar Of Physics Education, 1(1). https://doi.org/10.24036/492171074

Douglas, G. C. (2014). PHYSICS: Principles with Application (FISIKA: Prinsip dan Aplikasi) (I). Erlangga.

Fadli, A., Suharno, S., \& Musadad, A. A. (2017). Deskripsi Analisis Kebutuhan Media Pembelajaran Berbasis Role Play Game Education untuk Pembelajaran Matematika. Seminar Nasional Teknologi Pendidikan 2017. Seminar Nasional Teknologi Pendidikan 2017. https://www.neliti.com/publications/172289/deskripsi-analisiskebutuhan-media-pembelajaran-berbasis-role-play-game-educatio 
Hendriyani, Y., Delianti, V. I., \& Mursyida, L. (2018). Analisis Kebutuhan Pengembangan Media Pembelajaran Berbasis Video Tutorial. Jurnal Teknologi Informasi Dan Pendidikan, 11(2), 85-88. https://doi.org/10.24036/tip.v11i2.147

Kementerian Pendidikan dan Kebudayaan. (2017). Silabus SMA/MA Mata Pelajaran Fisika.

Kurniasari, I. (2018). Pengembangan E - Module Berbasis Exe-Learning Bercirikan Etnomatematika Pada Materi Bangun Ruang Peserta Didik Kelas VIII [Undergraduate, UIN Raden Intan Lampung]. http://repository.radenintan.ac.id/4285/

Lisyanti, D. (2019). Pengembangan E-Modul Matematika Berbasis Exe-Learning Pada Siswa Smp Kelas VII Skripsi [PhD Thesis]. UIN Raden Intan Lampung.

Mussoi, E. M. (2011). GeoGebr a and eX e Lear ning: Applic ability in the teac hing of $P$ hy $s$ ic $s$ and $M$ athem atic s. 9(2), 6.

Priyambodo, E. (2010). Pemanfaatan Program Aplikasi eXe (ELEARNING XHTML EDITOR) Dalam Penyusunan Media Pembelajaran Di Sekolah. Jurnal Pendidikan Kimia, $\quad$ FMIPA Universitas Negeri Yogyakarta. http://staffnew.uny.ac.id/upload/132309686/penelitian/eXe.pdf

Taulabi, I., \& Mustofa, B. (2019). Dekadensi Moral Siswa dan Penanggulangan melalui Pendidikan Karakter. Jurnal Pemikiran Keislaman, 30(1), 28-46.

Trilling, B., \& Fadel, C. (2009). 21st Century Skills.: Learning for Life in Our Times. John Wiley \& Sons.

Wyles, R. E.-L. D. at T. O. P. of N. Z. richard wyles@openpolytechnic ac nz. (2006, Oktober 30). New Zealand Open Source Virtual Learning Environment Project—A Case Study in Achieving National Development Goals using Open Educational Resources. The Fourth Pan-Commonwealth Forum on Open Learning (PCF4). http://pcf4.dec.uwi.edu/viewpaper.php?id=81

Yaumi, M., Sutopo, S., \& Parno, P. (2019). Pembelajaran Fisika Menggunakan Pemodelan Untuk Meningkatkan Pemahaman Konsep Pada Materi Hukum Newton Gravitasi Dan Hukum Kepler. Edu Sains Jurnal Pendidikan Sains \& Matematika, 7, 21-27. https://doi.org/10.23971/eds.v7i1.1001

Yuliharti, Y. (2019). Pembentukan Karakter Islami Dalam Hadis Dan Implikasinya Pada Jalur Pendidikan Non Formal. POTENSIA: Jurnal Kependidikan Islam, 4(2), 216-228. https://doi.org/10.24014/potensia.v4i2.5918 